\title{
Spontaneous Thrombosis of an Unruptured Saccular Aneurysm Causing MCA Infarction
}

\author{
Anton Fomenko, Anthony M. Kaufmann
}

\begin{abstract}
Spontaneous complete thrombosis of an unruptured intracranial aneurysm leading to ischemic stroke is rare. We present a case of a 56-year-old man who suffered an acute left middle cerebral artery (MCA) infarction, attributable to complete thrombosis of an unruptured saccular MCA bifurcation aneurysm with occlusion of the parent artery. The presenting hemiparesis and aphasia partially improved over a long hospital rehabilitation stay. Follow-up imaging demonstrated no recanalization of the aneurysm or parent vessels. To the best of our knowledge this is the first documented case of isolated MCA territory infarction due to complete spontaneous thrombosis of a saccular aneurysm.
\end{abstract}

RÉSUMÉ: Thrombose spontanée d'un anévrisme sacculaire non-rupturé ayant causé un infarcissement de l'artère cérébrale moyenne. Les cas spontanés de thrombose totale d'un anévrisme sacculaire non-rupturé menant à un accident vasculaire cérébral (AVC) ischémique sont rares. Nous voulons ici présenter le cas d'un homme de 56 ans victime d'un infarcissement aigu de l'artère cérébrale moyenne (ACM) gauche ayant été causé par la thrombose totale d'un anévrisme sacculaire non-rupturé. À noter que des manifestations d'hémiparésie et d'aphasie ont en partie diminué à la suite d'un long séjour de réadaptation à l'hôpital. Un examen de suivi par imagerie n'a pas révélé de recanalisation de l'anévrisme ou des vaisseaux sanguins principaux. À notre connaissance, il s'agit là du premier cas documenté d'infarcissement d'une ACM isolée provoqué par une thrombose spontanée et totale d'un anévrisme sacculaire.

Keywords: Stroke, neuroimaging, aneurysms

doi:10.1017/cjn.2016.282

Can J Neurol Sci. 2016; 43: 856-858

\section{INTRODUCTION}

The prevalence of unruptured intracranial aneurysms (UIA) as an incidental finding has been cited from less than $1 \%$ to as high as $9 \%$ depending on study methodology and patient demographics. ${ }^{1}$ Studies have found some degree of intra-aneurysmal thrombosis in up to $9 \%$ of patients with ruptured and unruptured aneurysms. ${ }^{1}$ Only a few cases document spontaneous thrombosis of an UIA resulting in ischemic stroke. ${ }^{2-4}$ To the best of our knowledge our case is unique in describing complete thrombosis of an MCA bifurcation unruptured aneurysm with occlusion of the parent artery and resulting ischemic stroke of its entire vascular territory.

\section{Case Report}

A 56-year-old right-handed man was admitted to hospital for acute-onset global aphasia and dense right hemiparesis. His past medical history was notable only for smoking and acid reflux. He had awoken in the morning feeling well and was witnessed by his wife leaving for work without incident. The patient's coworkers called the ambulance in the afternoon after noticing sudden confusion, unintelligible speech and unsteadiness. On admission to the emergency department vital signs were within normal limits.

On initial neurological examination the patient was alert and had flaccid hemiplegia of his right face, arm and leg. He had neglect of his right visual field and severe receptive and expressive aphasia. Relevant bloodwork such as partial thromboplastin time, international normalized ratio, and liver function tests were all normal.

Initial computed tomography (CT) scans demonstrated a thrombosed MCA aneurysm $(1.8 \times 1.3 \times 1.0 \mathrm{~cm})$ with associated occlusion of the left MCA at its bifurcation (Figure 1). There was no evidence of subarachnoid hemorrhage or intracerebral blood. There was loss of grey-white differentiation in the left insular, frontal and parietal lobes. The initial Alberta Stroke Program Early CT score was 2, indicating an established stroke with diffuse MCA involvement. As such, stroke mitigation by endovascular or surgical revascularization was not pursued. The next day magnetic resonance imaging (MRI) and MR angiography (MRA) confirmed a large area of ischemic acute infarction in the left MCA territory and extremely poor opacification of distal left MCA branches (Figure 2).

The patient had an uncomplicated hospital stay in the neurosurgical ward, was started on acetylsalicylic acid and clopidogrel, and was eventually transferred to the stroke rehabilitation unit. Prolonged Holter monitor demonstrated no evidence of arrhythmia, an Echocardiogram showed no intracardiac abnormality, and carotid CT Angiogram (CTA) showed no significant stenosis. Follow-up CTA performed 2 and 9 months post-stroke showed no intra-aneurysmal flow and no change in the morphology of the aneurysm dome, wall or thrombus. Partial recanalization of the M1 segment was seen at the MCA bifurcation, though with persistent attenuation of distal MCA branches (Figure 3). Therefore continued surveillance with serial neuroimaging and clinical follow-up is planned.

From the University of Manitoba, Section of Neurosurgery, Winnipeg, Manitoba, Canada (AF, AMK).

Received October 13, 2015. Final Revisions Submitted March 16, 2016. Date of ACCEPTANCE May 6, 2016.

Correspondence to: Anton Fomenko, Section of Neurosurgery, University of Manitoba, Winnipeg, Manitoba, Canada. Email: fomenkoa@myumanitoba.ca 


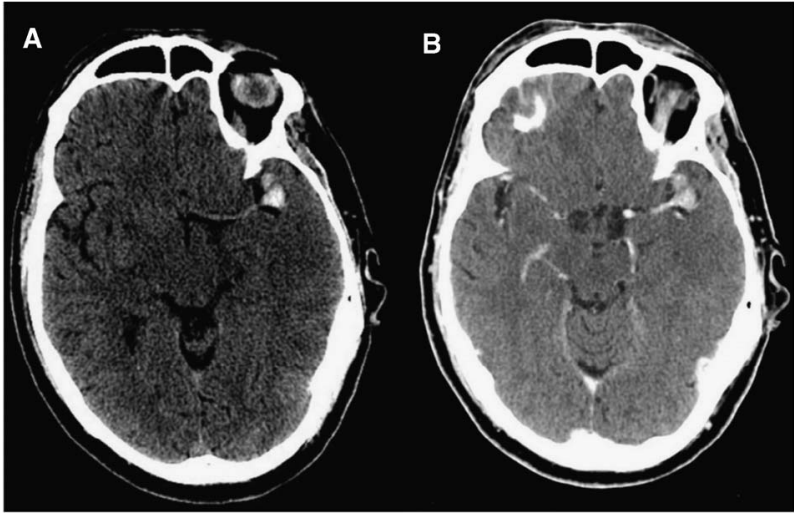

Figure 1: Initial uninfused $(A)$ and infused (B) CT demonstrating hyperdensity at the left MCA bifurcation representing an acutely thrombosed aneurysm with occlusion of the parent vessel and early MCA territory infarction.

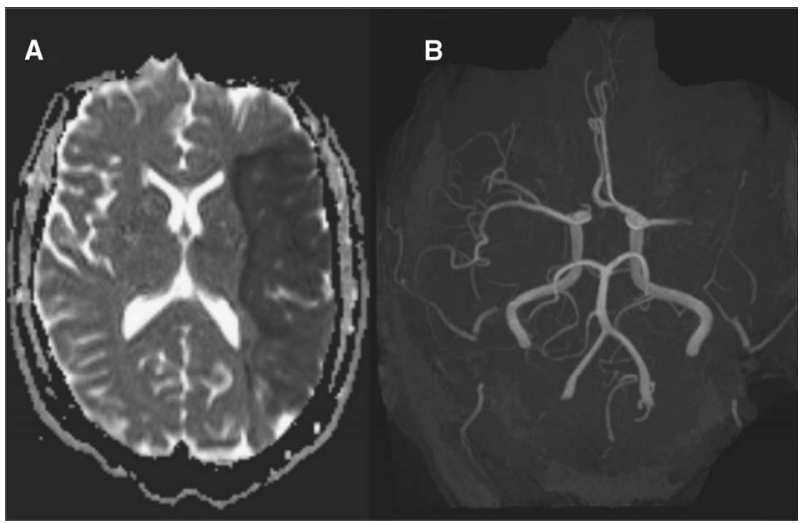

Figure 2: MR sequences demonstrating (A) acute left MCA territory infarction on diffusion weighted imaging $(B)$ and complete occlusion of distal MCA vessels at its bifurcation on MRI time of flight 3-D reconstruction.

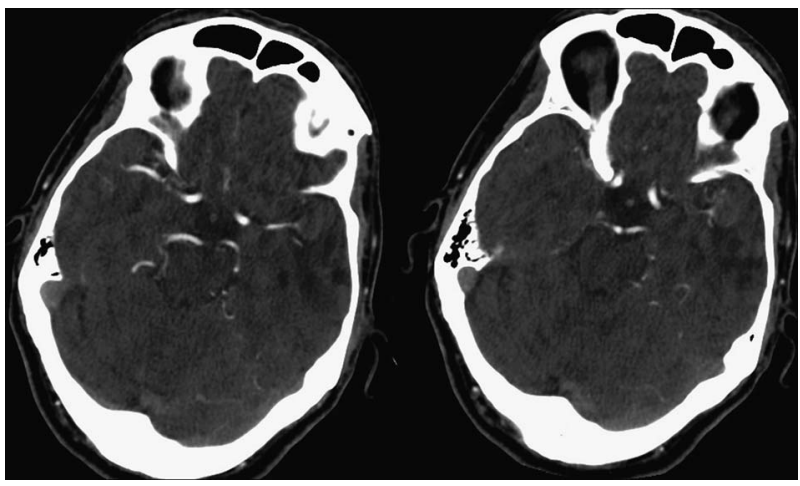

Figure 3: Follow-up CT Angiogram 11 weeks post-stroke demonstrating unchanged aneurysmal geometry and intensity, with partial recanalization of a distal M2 segment.

\section{DISCUSSION}

The natural history of thrombosed aneurysms is not well known. The presence of partial thrombosis has not generally been shown as protective against aneurysm rupture, although it has been associated with distal embolization leading to transient ischemic attacks and infarction. Exceptional case reports have demonstrated spontaneous complete thrombosis of cerebral aneurysms which, despite being angiographically silent, may not necessarily protect against future rupture. ${ }^{5}$ There are only a few cases in the literature documenting spontaneous complete thrombosis of an UIA with occlusion of the parent artery and resulting ischemic stroke. Brownlee ${ }^{2}$ described thrombosis of an anterior communicating artery aneurysm in a 66-year old woman, resulting in fatal ischemic infarctions. Whittle ${ }^{3}$ described successful aneurysmectomy and thrombectomy of a giant intracavernous carotid aneurysm that had thrombosed and occluded the carotid artery. Cohen ${ }^{4}$ described a series of three patients where completely thrombosed aneurysms caused distal infarcts in the anterior communicating, PICA and PCA territories, respectively.

Several theories of the pathophysiology of aneurysm thrombosis have been proposed based on animal and computational models. German and Black ${ }^{5}$ used an in vivo canine model to demonstrate that higher rates of spontaneous aneurysm thrombosis were associated with a narrower aneurysm orifice and more voluminous dome. Kikut $^{6}$ studied patterns of intra-aneurysmal blood flow with diaphanoscopy in explanted human specimens and found three distinct zones within the aneurysm: one with turbulence, one with nearly normal flow and one region near the apex of the dome where flow was nearly stagnant. Preliminary simulations of intra-aneurysmal hemodynamics have also been conducted with the aid of increasingly sophisticated threedimensional computer algorithms. Mathematical models of MCA aneurysms from images acquired by three-dimensional CTA have shown an inverse relationship between the dome-toneck ratio of the aneurysm and the average intraluminal flow velocity. ${ }^{7}$ This may help explain the higher rates of thrombosis in large and giant aneurysms. In addition, areas of stasis and recirculation were consistently found at the tip of the dome, a common area of observed thrombosis. Intra-aneurysmal platelet aggregation in portions of the aneurysm with relatively stagnant intraluminal flow may thereby foster an environment for thrombosis.

Recurrent intramural hemorrhages are another potential mechanism underlying aneurysmal thrombosis. Neuroimaging studies have found acute clots at the periphery of thrombosed giant aneurysms, and surgical series of large or giant aneurysms commonly cite intramural or intraluminal thrombosis as a pathological finding in up to $60 \%$ of treated lesions. The fragile vasa vasorum that encapsulates large aneurysms may bleed into the subadventitial aneurysmal wall, contributing to intramural thrombosis. This mechanism is analogous to the neovascularized membrane of a chronic subdural hematoma bleeding and contributing to the enlargement of the collection. In a series of ten patients with giant aneurysms imaged with MRI, nine (90\%) showed areas of $\mathrm{T} 1$ hyperintensity, suggestive of fresh clot distal to the parent vessel and within the thrombus. Three of five patients administered gadolinium showed partial or complete rim enhancement at the margin of thrombus, suggestive of extravasation consistent with the aforementioned theory. ${ }^{8,9}$ Pathological studies have also revealed intrathrombotic capillary channels with endothelial lining surrounded by staged clots, suggesting that intra-aneurysmal thrombus may neovascularize, bleed and thereby enlarge from within. In our case, the aneurysm was homogeneously hyperdense on uninfused CT, indicating an acute event, while the MRI demonstrated a recent blood product age. There was no evidence of longstanding or organized thrombosis, making this etiology unlikely. 
Complete occlusion of the aneurysm with thrombus is associated with a very low risk of future rupture. ${ }^{9,10}$ However, delayed recanalization of the dome has been described in a case report of completely thrombosed PCA aneurysm, which was subsequently treated with trapping and aneurysmectomy. ${ }^{9,10}$ Similarly, studies have reported aneurysm rupture following thrombosis induced by flow diversion (FD) treatment. ${ }^{9,10}$ Follow-up imaging is therefore important to identify any aneurysm recanalization that may warrant treatment.

In summary, we present a unique case of an unruptured MCA bifurcation aneurysm presenting with an acute stroke due to complete thrombosis of the aneurysm and parent vessel. Factors contributing to thrombosis in this case are unknown but may include flow stasis within the dome of a large unruptured aneurysm. Thromboembolic workup was negative. Late 9-month follow-up imaging revealed no intra-aneurysmal flow, but did demonstrate partial recanalization of the parent vessel. Continued clinicoradiological surveillance is planned.

\section{Disclosures}

Anton Fomenko and Anthony Kaufmann do not have anything to disclose.

\section{REFERENCES}

1. Lawton MT, Quinones-Hinojosa A, Chang EF, Yu T. Thrombotic intracranial aneurysms: classification scheme and management strategies in 68 patients. Neurosurgery. 2005;56:441-54.

2. Brownlee RD, Tranmer BI, Sevick RJ, Karmy G, Curry BJ. Spontaneous thrombosis of an unruptured anterior communicating artery aneurysm. Stroke. 1995;26:1945-9.

3. Whittle IR, Williams DB, Halmagyi GM, Besser M. Spontaneous thrombosis of a giant intracranial aneurysm and ipsilateral internal carotid artery. Case report. J Neurosurg. 1982;56:287-9.

4. Cohen JE, Itshayek E, Gomori JM, Grigoriadis S, Raphaeli G, Spektor S, Rajz G. Spontaneous thrombosis of cerebral aneurysms presenting with ischemic stroke. J Neurol Sci. 2007; 254(1-2):95-8.

5. German WJ, Black SPW. Experimental production of carotid aneurysms. New England J. Med. 1954;250(3):104-6.

6. Kikut RP. Experimental investgations of intraaneurysmal blood flow. Vopr Neurosurg. 1966;2:17-21.

7. Shojima M, Oshima M, Takagi K, Torii R, Hayakawa M, Katada K, Morita A, Kirino T. Magnitude and role of wall shear stress on cerebral aneurysm: computational fluid dynamic study of 20 middle cerebral artery aneurysms. Stroke. 2004;35(11):2500-5.

8. Teng MM, Qadri SMN, Luo CB, Lirng JF, Chen SS, Chang CY. MR imaging of giant intracranial aneurysm. J Clin Neurosci. 2003; 10:460-4.

9. Lee KC, Joo JY, Lee KS, Shin YS. Recanalization of completely thrombosed giant aneurysm: case report. Surg Neurol. 1999; 51:94-8. 